Article

\title{
The Business Process Model and Notation Used for the Representation of Alzheimer's Disease Patients Care Process
}

\author{
Martin Kopecky ${ }^{+}$(D) and Hana Tomaskova ${ }^{*}+$ (D) \\ Faculty of Informatics and Management, University of Hradec Kralove, Rokitanskeho 62, \\ 50003 Hradec Kralove, Czech Republic; martin.kopecky@uhk.cz \\ * Correspondence: hana.tomaskova@uhk.cz \\ t These authors contributed equally to this work.
}

Received: 08 October 2019; Accepted: 22 January 2020; Published: 4 February 2020

\begin{abstract}
Currently, the number of patients with neurological diseases is increasing, especially those older than 65 suffering from Alzheimer's disease. This development increases the emphasis on understanding and mapping treatment and care processes, not only for the elderly. Service providers (of both treatment and care) are under general pressure to decrease charges and maintain or improve existing levels of care. This situation is significantly influenced by a comprehensive knowledge of the whole process and its values. This publication therefore aims to describe the fundamental procedural aspects of caring for patients with Alzheimer's disease, using Business Process Model and Notation (BPMN). It also aims to show the possibilities of using BPMN in the description of treatment and care. Modeling of the business process is more frequently being applied not only by businesses but also by scientists involved in process models. It is used to model medical topics, with approximately $10 \%$ of its publications only, and most of these publications deal only with clinical pathways, not with overall treatment and care processes. However, the BPMN model allows the whole process of medical and nonmedical care for patients with Alzheimer's disease to be described, including the decomposition of partial activities into individual threads and sub-processes or atomic tasks. This paper presents the BPMN modeling and mapping of the specific care path for neurodegenerative patients. The text provides a new perspective on the BPMN modeling of Alzheimer's disease. The presented model offers the option of expanding treatment cost calculation to simulate the process using graphical tools and languages. The overall view of this system creates a much more complex concept of the system and its surroundings.
\end{abstract}

Keywords: Business Process Model and Notation; BPMN; process modeling; Alzheimer's disease; clinical pathways; care path; cost management

\section{Introduction}

The dimensions and structure of the population will continue to be subject to dramatic changes due to both low birth rates and the constant increase in life expectancy. This trend will have a significant influence on the composition and, above all, care of the population. It is necessary to specify the processes of care in terms of both the continually increasing receivables and the increasing number of persons in need.

Approximately 50 million people in the world are affected by dementia [1]. This value will probably grow to 152 million by 2050. It is well known that dementia is an age-related disease. More than 200 subtypes of dementia have been identified, and more than half of dementia cases are induced by Alzheimer's disease (AD). The possibility of an AD outbreak rises 14-fold for people 
between the ages 65 to 85 and affects more or less $47 \%$ of people older than 85 years of age [2]. The gradual deterioration of cognitive functions characterizes this disease. Understanding, describing, and illustrating the processes of caring for and treating Alzheimer's patients is a significant problem in many institutions and societies.

This research study aimed to create a process model of treatment procedures and supplementary care processes for patients with Alzheimer's disease. The presented model includes processes applicable to all three phases of the disease, pharmacological and non-pharmacological treatments, and home and institutional care processes. The identification of individual steps and their construction is necessary for the following applications: costing and simulation, predictive quantitative models, and preferential simulations. In addition to pharmacological-neurological questions, two other key questions need to be asked with regard to Alzheimer's disease. The first is, how much do treatment and patient care cost? The second question is, how many Alzheimer's patients are there, and how many will there be in the future? Patients with AD are often treated with and assigned to other patient groups, so there are no exact figures relating to these patients. These issues are critical for health insurance companies, care center founders, and welfare offices. The process model presented in this article will be provided to these authorities, along with other findings. The calculations for the costs of activities have already been published and are briefly described in the paragraph below. The process model presented in Section 4 contains a significant number of decision nodes. In further research, we will build on the existing model by linking the Business Process Model and Notation (BPMN) model with fuzzy approaches. This approach will serve as a basis for the decision-making of individual agents in multi-agent simulations, which should complement and summarize the present contributions to AD questions in the Czech Republic.

The issue of modeling Alzheimer's disease processes and treatments has been addressed in various ways; some are listed in the "Related Works" section of this paper. Our research group has been working on Alzheimer's models for several years, during which time we have cooperated with University Hospital Hradec Králové, nursing facilities, as well as health insurance companies. The first results of our research described the use of system dynamics to estimate the population of Alzheimer's patients and predict the development of these patients [3-7]. These estimates were crucial indicators influencing the planning of care-center capacities and proposed state and private funding. Subsequently, our group began to investigate the financing of care and treatment from an overall perspective. There are cost values for some activities and some items in the healing and nursing process, but there is no overall view or simulation environment. Therefore, our group developed a simulation model using BPMN and linked it to activity-based costing (ABC) in a simulation model $[8,9]$. However, the preparation of this model demonstrated how few scientific papers are devoted to the description and modeling of treatment and care for Alzheimer's patients. The numbers of publications found in a search for the keywords "BPMN" and "Alzheimer" are shown in Table 1. The search was undertaken without evaluating the relevance of the results.

Table 1. Number of publications found in a search for "BPMN" and "Alzheimer".

\begin{tabular}{ll}
\hline Database & Searched Publications \\
\hline Web of Science & 2 \\
Scopus & 8 \\
IEEE Xplore & 0 \\
ACM Digital Library & 0 \\
Google Scholar & 126 \\
\hline
\end{tabular}

The low number of publications we found led us to the goal of this article: to describe the fundamental procedural aspects of caring for patients with Alzheimer's disease using Business Process Model and Notation, and to show the possibilities for using BPMN in the description of treatment and care. 
The rest of this paper is organized as follows. Section 2 provides a discussion of related works. Section 3 presents the theoretical background. The first part introduces Alzheimer's disease and the second part describes business process management and BPMN. Section 4 describes the BPMN model of Alzheimer's treatment and care. The process presents the individual steps and activities of treatment and patient care for all three stages of the disease. Section 5 presents the limits and benefits of this study. Section 6 presents the conclusions reached by this study.

\section{Related Works}

Treatment and patient care processes are hot topics as a result of the increasing numbers of elderly and sick people. Many authors are involved in publications on this topic, and several approaches have been used. The purpose of the study in [10] was to recognize, organize, and explain the observed requirements of older dementia patients through the care process. Rinner et al. [11] used the process mining approach to show how existing clinical data collected during melanoma monitoring can be prepared and preprocessed to be reused for process extraction. The article by Martínez Pérez et al. [12] focuses on introducing to the intensive care unit (ICU) a core service with unique features that automates and monitors admissions, care plans, vital signs monitoring, directing, and medication delivery to patients in the ICU. In [13], the authors describe the contentment of the patients with pre-hospital emergency know-how. They focus on deciding if patients and specialists share a comparable vision of welfare assumptions. Authors in [14] present the use of technology-based in-home care as a potential benefit, such as improving the quality of care. This approach means a full concentration on the patient's role in controlling their fitness and more extensive patient commitment in the treatment.

Healthcare and patient care is a topical issue, which is currently solved not only in terms of knowledge of processes but also in the solution of financial and human resources [15,16]. The arrangement of procedures and capital allocation for operations has a significant role in reaching the expected service level and profitability. Different approaches and applications have been used to work in this area. The authors in [17] presented research on four medical applications. Each application had to use clinical and administrative functions. The research results were then used to determine the requirements for the development of a new application. Already in 2007, the authors in [18] put forth that process mining can be successfully used to support the discovery of processes in the healthcare sector [19]. The goal of process mining is to analyze the complex temporal relationships between activities and resources involved in processes [20]. García et al. [21] used process mining for analysis and modeled processes in the Emergency area. Authors in [22] proposed a methodology for identifying and mapping patient flows through the extraction process. Pereira Detro et al. [23] offer a process model adapting the method based on ontology and process mining. In [24], a process extraction and machine learning approach for electronic health record (EHR) analysis with discrete event simulation (DES) and queuing theory was proposed.

Alzheimer's disease has been predominantly studied from the perspective of chemistry and medicine [25-30]. Since so much is unknown about AD, some articles seek to predict these unknowns [3-5,31,32], while others use artificial intelligence or advanced decision-making methods to address related issues [33-35]. Research on AD is also very closely associated with the financial costs of treatment, so there are many publications in this area as well [36-42]. In the field of IT, for example, modern technologies are presented for Alzheimer's disease in training programs, assistive technologies, intelligent environment, etc. [43-46]. The use of modeling techniques to calculate the cost of treatment for $\mathrm{AD}$ is relatively unique, we can mention for example, the works [7-9,47-49] . 


\section{Theoretical Background}

\subsection{Alzheimer's Disease}

Neurodegenerative diseases are most often caused by Alzheimer's disease (AD) $[50,51]$. Neurodegenerative diseases are untreatable and debilitating conditions that result in the progressive degeneration or death of nerve cells, which causes problems with movement (ataxia) or with mental functions (dementia). Dementia is responsible for the most significant share of the disease, with Alzheimer's disease accounting for approximately $60 \%-70 \%$ of cases.

$\mathrm{AD}$ is a prolonged illness represented by sneaking inception, which may not be apparent at first glance. In the case of a typical course, it is a rather lengthy illness. Generally, the length of disease ranges from 6 to 16 years, but this is wholly dependent on the individual case. People with AD gradually experience various difficulties with memory, continuing to experience problems in communication and everyday life. In the final phase, the patient needs complete assistance from others.

Alzheimer's disease can be diagnosed by many different medical examinations. The primary tool is magnetic resonance imaging, which monitors brain changes. Infrequently, cerebrospinal fluid or blood are also examined. The Mini-Mental State Examination (MMSE) is used as a first examination, representing a compromise approach [52,53]. A psychiatrist asks the patient a sequence of questions to test their scope of ordinary cognitive abilities. The scale of this test is from 0 to 30 points.

Three primary stages of AD will be presented in this section. Symptoms are taken from [54].

1. Stage-Mild Alzheimer's disease (early stage) lasts up to 4 years: difficulty in dealing with new experiences (e.g., in new premises), problems with short-term memory; more trivial errors from an inability to maintain attention, difficulty with complex logical operations, and mood swings to obsessive states; beginning communication problems.

2. Stage-Moderate Alzheimer's disease (middle stage) is in the range of 2-10 years from the onset of the disease: difficulty in performing routine activities, difficulties remembering known places, inability to concentrate, forgetting what one wanted to do, need for assistance in dressing/personal hygiene, psychological problems including entering into hallucinogenic and delusional states, almost inoperative short-term memory.

3. Stage-Severe Alzheimer's disease (late stage) breaks out within about 7-14 years of disease. This is the final degree of the disease, ending with the patient's death. The patient is already fully dependent on the environment, has absolute memory loss, inability to perform the simplest activities, has need of food assistance, personal hygiene, apathetic and latent states.

\subsection{Business Process Management}

Business process management is a management discipline focused on using business processes to obtain the company's objectives.

BPMInstitute.org [55] defines business process management as the definition, improvement, and management of a firm's end-to-end enterprise business processes to achieve three outcomes crucial to a performance-based, customer-driven firm: (1) clarity on strategic direction, (2) alignment of the firm's resources, and (3) increased discipline in daily operations.

\section{The Business Process Model and Notation}

The Business Process Model and Notation (BPMN) is a visual notation that allows modeling of the manner of business behavior. This approach has been specially constructed to coordinate the timeline of activities between different process participants [56].

The book [57] describes BPMN as a language for creating business process models. It is a standard for modeling business processes. The Object Management Group (OMG) was created as an open resource, and is therefore free of charge. BPMN looks very similar to flowcharts but instead offers much more sophisticated tools to describe and simulate behavior. 
BPMN makes it possible to model not only the desired behavior of a process, but above all other situations and exceptions that can occur. Another very significant feature of BPMN is its "user-friendly" orientation. For comparison, we can focus on the Unified Modeling Language (UML) and its Activity diagram, which is often used to model the same situations. However, unlike BPMN, UML is an orientation in IT usage. In this case, BPMN offers a more intuitive and logical application in normal situations [58-60]. BPMN is one of the BPM (business process management) tools defined in [61] as a "combination of methods, techniques, and tools to discover, analyze, redesign, execute and monitor business processes."

The use of BPMN is defined in the Reference Manual [62]. Elements are also logically structured into groups, depending on how they can be used in modeling and what they represent in the diagram.

- Flow objects are the crucial components used to describe the action of the business process. This group includes three main elements: Events, Activities, and Gateways. Events serve to model the "Something Happened" situation. They are always labeled with a circle where their shape and the symbol inside specify the type of event. By activity is meant the work that is built into the process. The atomic activity is the task; more complicated is the sub-process (can be decomposed into individual tasks or sub-processes). The gateway serves to control the flow of the process when the process fibers are merged or split. Gates do not represent any work or action during the process.

- Swimlanes are used to identify the boundaries of the communication objects. The pool is used to view the process or participant, and the Lane can be used to split the Pool into other parts.

- Connecting objects are used to connect different BPMN elements in different locations-the notation comprises three main types: Sequence, Message, and Association Flow. Sequence Flows mean process progress. For this reason, the boundaries of one Pool can never be crossed. Message Flows serve to illustrate communication between individual participants or Pools. The Association Flow connects information and artifacts with other BPMN elements.

- One of the necessities in modeling processes is the ability to model work with data objects (physical or information) in terms of their creation, change, and manipulation. These elements that are meant to be stored or mediated during the process are named as Artifacts.

\section{The BPMN Process of AD Patients' Treatment and Care}

The process of treating patients with Alzheimer's disease and providing the necessary care is a complex and variable problem. It requires a great deal of soft data and previous practice. From interviews with competent persons, it was found that no precise plan was set for such a changing process. Therefore, from these interviews, we have compiled with these experts the overall process of medical and non-medical care for Alzheimer's patients, which allows the future extension to process simulations and comparison with the outputs of the process mining analysis. The length of the particular stages of the disease cannot be determined in the process, and therefore, possible changes in the patient's state are conditioned by the MMSE test's values.

Each AD phase has a differently defined activities complexity. Medicaments are usually changed with disease progression and changes in the type of patient care. In the early stages of the disease, the focus is on slowing the disease progression and patient's conservation in a normal life mode. In the next steps, care is more focused on minimizing impacts and quality of life.

The overall model describing the main activities is presented below.

\subsection{The BPMN Process of Medical and Non-Medical Care}

The process of medical and non-medical care of Alzheimer's disease patients (shown in Figure 1) begins with the indication of initial symptoms (the Start event). After the initial examination, care is initiated according to the severity of the symptoms found or the specified stage of the disease. Sub-process treatment begins with a medical examination, after which the process can decide in which of the three phases the patient is located. This corresponds to initiated treatment and care. The process 
then follows a decision node that either terminates the sub-process, completes the third final stage of the disease, or resumes the medical examination process and repeats the cycle. Due to the incurability of the disease, a patient's death ends the treatment and care.

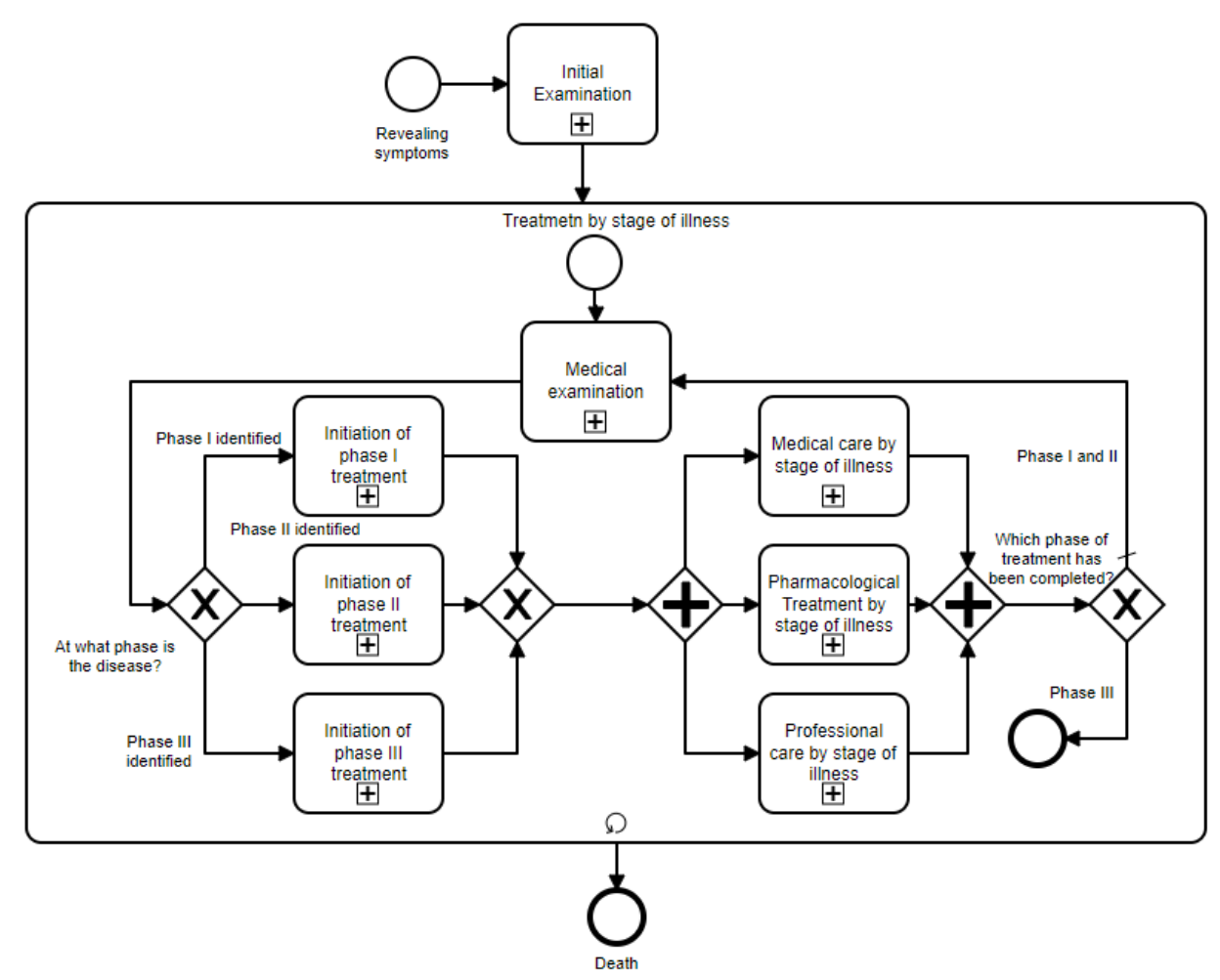

Figure 1. Alzheimer's disease Business Process Model and Notation (BPMN) process.

\subsubsection{Sub-Process: Initial Examination}

A patient with suspected Alzheimer's disease enters the "Initial Examination" thread, where necessary neurological and psychiatric examinations are performed. This thread is shown in Figure 2. Blood and cerebrospinal fluid are also examined in this path. All screenings are split in parallel at the beginning of the process, and after their merging, the MMSE score is determined.

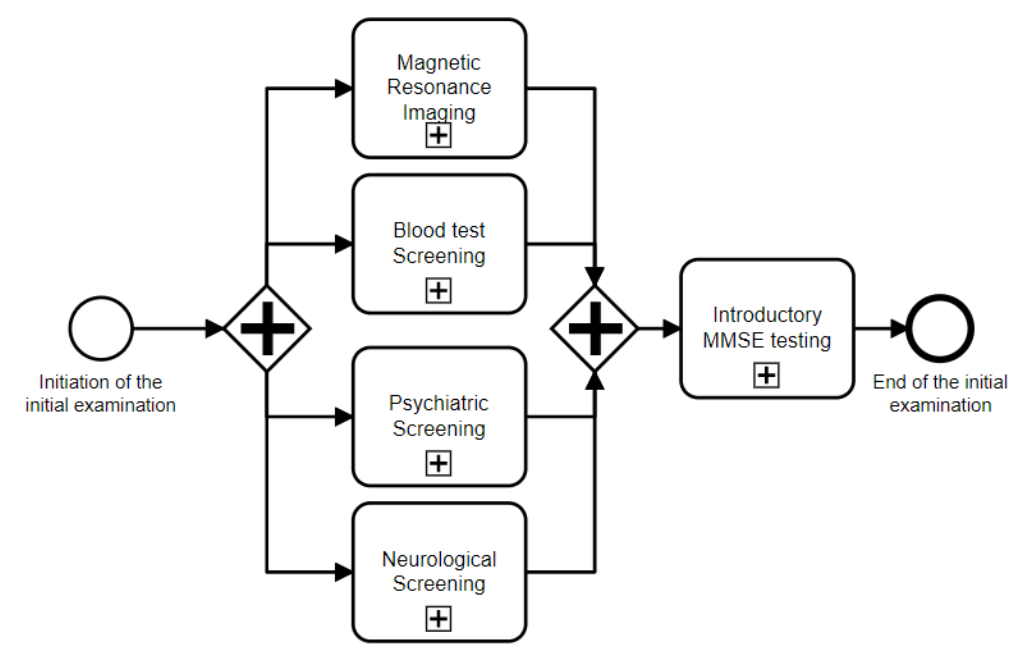

Figure 2. Initial examination BPMN sub-process. MMSE: Mini-Mental State Examination. 


\subsubsection{Sub-Process: Medical Examinations}

The "Medical Examinations" path shown in Figure 3 contains the activities associated with the medical tests that are necessary for the patient's examination during the illness. It is an archetypal parallel split into four sub-processes.

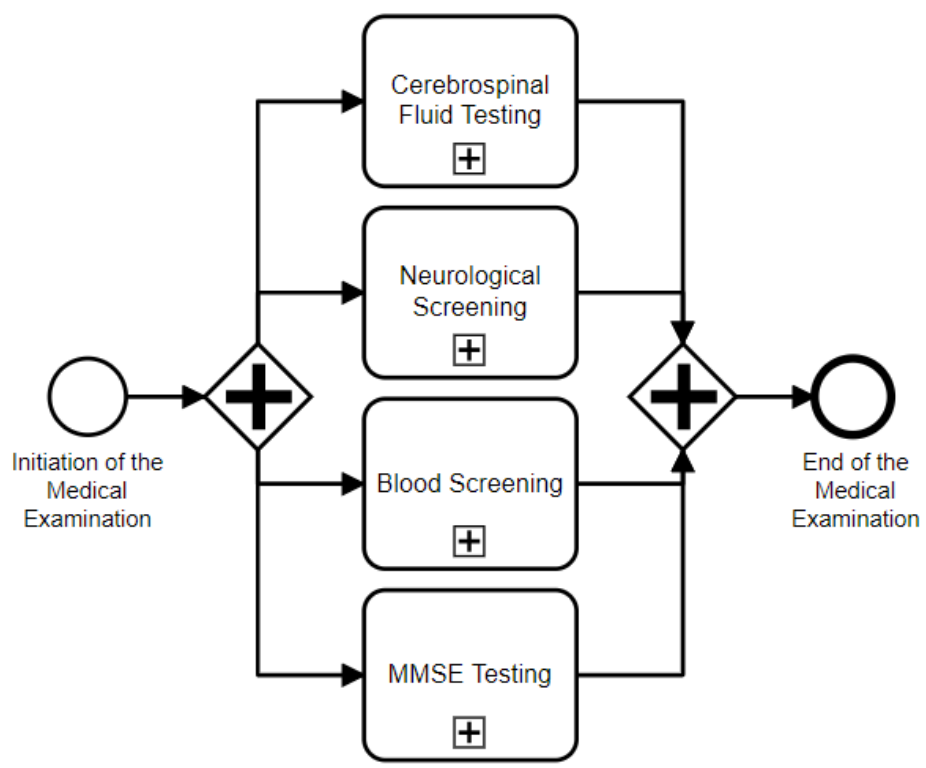

Figure 3. Medical examinations BPMN sub-process.

\subsubsection{Sub-Process: Pharmacological Treatment}

Figure 4 shows treatment with different types of drugs during the disease phases. Each phase requires the administration of specific medications. At the beginning of the process, the course of activity is branched to start treatment with Prozac and determine the MMSE score. The branch is divided according to the MMSE test result. If there is a drop of more than 2 points of the MMSE score, the process is terminated. In the case of a minor decrease, appropriate treatment is started according to the MMSE score. After this treatment, the MMSE score is determined again, and the cycle is repeated.

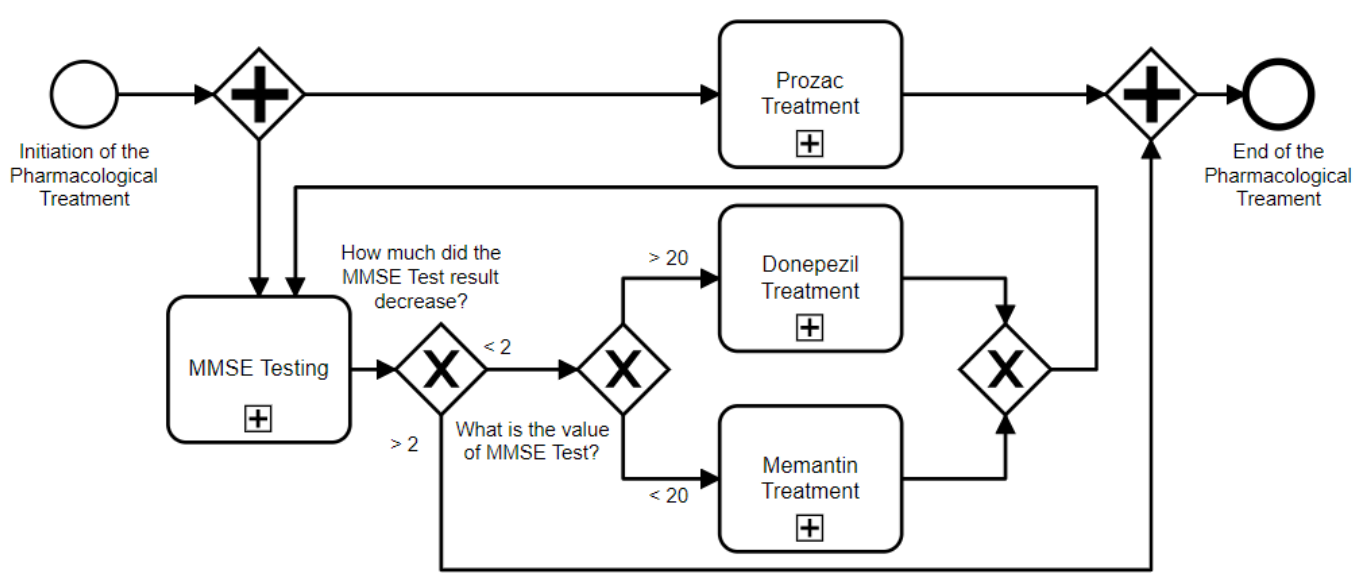

Figure 4. Pharmacological treatment BPMN sub-process.

\subsubsection{Sub-Process: Professional Care}

The "Professional Care" activities shown in Figure 5 include patient care resources that are performed by healthcare professionals. All sub-processes run in monthly cycles. At the beginning of 
the sub-process, it is decided whether care will be provided by being placed in a specialized facility or by a home care solution. The main home care activities are "Complex Care and Rehabilitation" activities, whose costs vary according to the MMSE score. In the case of home care, it is necessary to provide activities such as music therapy, rehabilitation, or other activation activities. Another part of home care is the "Other Cost Activities" sub-process. The second part of the flow, which is the first gateway allocated in this thread and stands alone, is placing the patient in a specialized facility for patients with Alzheimer's disease.

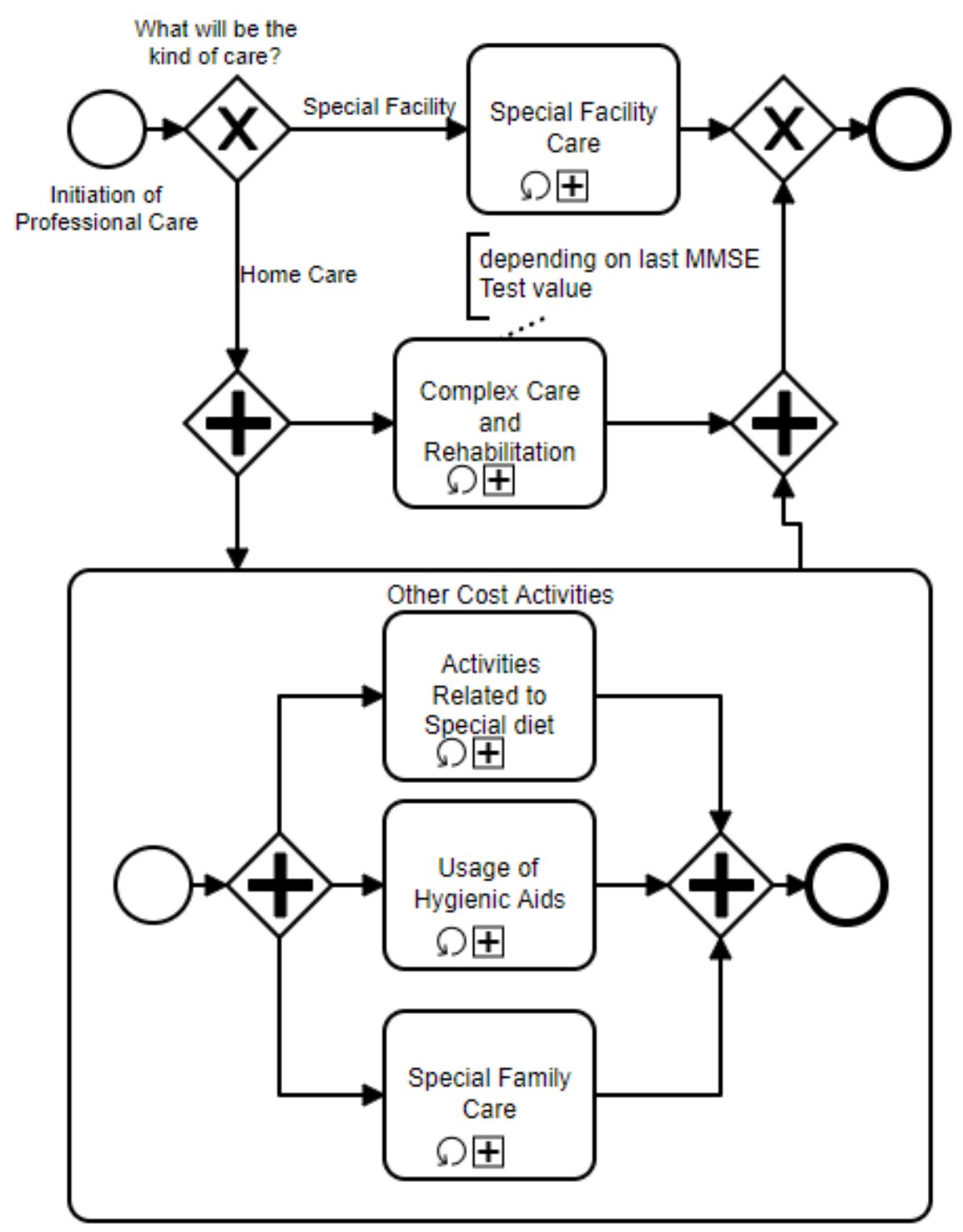

Figure 5. Professional care BPMN sub-process-Phase III.

\section{Discussion}

The contribution is limited by available information on the course of treatment and care of Alzheimer's patients in all three stages of the disease. Data were obtained from available literature and legislative standards for the Czech Republic, from interviews with doctors of the University Hospital in Hradec Králové and standardized regulations of health insurance companies and care facilities. The text presents an overview of a comprehensive model of treatment and care of patients with Alzheimer's disease using BPMN. It is therefore limited to a static description of activities during the illness. The model was used for simulation analysis using the activity-based costing method, and we expect further use for comparison with the outputs of process mining data analysis. 
The benefit of this publication is shown in the demonstration of the use of BPMN to illustrate the complex process of treatment and care of Alzheimer's patients.

\section{Conclusions}

This paper presents the application of BPMN to the process analysis of Alzheimer's disease. The created model shows the current course of the care process in the Czech Republic. The proposed model was developed based on interviews with doctors and care providers as well as available legislation. The model could be extended to include cost care items during the three phases of Alzheimer's disease. According to the proposed model, the simulations would allow us to determine the average cost of care for Alzheimer's patients in the Czech Republic.

In the BPMN model, it is planned to specify the conditions of transition between different stages of the disease and to diagnose and treat the individual symptoms. In this model, it would be possible to simulate different disease patterns at different time intervals. Currently, there is insufficient detail to describe the course of the disease and its formulae. This approach can therefore be seen as a detailed insight and a proposal for a path to interdisciplinary research on the border of medicine and the economy supported by IT simulations.

Author Contributions: Conceptualization, H.T. and M.K.; methodology, H.T.; validation, H.T.; investigation, M.K.; writing-original draft preparation, H.T. and M.K.; All authors have read and agreed to the published version of the manuscript.

Funding: This work was supported by a GACR 18-01246S and the Faculty of Informatics and Management UHK Specific Research Project.

Acknowledgments: This work was supported by a GACR 18-01246S and the Faculty of Informatics and Management UHK Specific Research Project.

Conflicts of Interest: The authors declare no conflicts of interest.

\section{References}

1. Vasic, V.; Barth, K.; Schmidt, M.H. Neurodegeneration and Neuro-Regeneration-Alzheimer's Disease and Stem Cell Therapy. Int. J. Mol. Sci. 2019, 20, 4272. [CrossRef] [PubMed]

2. Yankner, B.A.; Lu, T. Amyloid $\beta$-protein toxicity and the pathogenesis of Alzheimer disease. J. Biol. Chem. 2009, 284, 4755-4759. [CrossRef] [PubMed]

3. Cimler, R.; Tomaskova, H.; Kuhnova, J.; Dolezal, O.; Pscheidl, P.; Kuca, K. Numeric, Agent-based or System Dynamics Model? Which Modeling Approach is the Best for Vast Population Simulation? Curr. Alzheimer Res. 2018, 15, 789-797. [CrossRef] [PubMed]

4. Tomaskova, H.; Maresova, P.; Jun, D.; Augustynek, M.; Honegr, J.; Klimova, B. Dynamic Modeling of the Czech Republic Population with a Focus on Alzheimer's Disease Patients. In Proceedings of the ACIIDS, Dong Hoi, Vietnam, 19-21 March 2018; pp. 347-356.. [CrossRef]

5. Tomaskova, H.; Kuhnova, J.; Cimler, R.; Dolezal, O.; Kuca, K. Prediction of population with Alzheimer's disease in the European Union using a system dynamics model. Neuropsychiatr. Dis. Treat. 2016, 12, 1589-1598. [CrossRef] [PubMed]

6. Maresova, P.; Tomaskova, H.; Kuca, K. The Use of Simulation Modelling in the Analysis of the Economic Aspects of Diseases in Old Age. In Proceedings of the 14th Eurasia Business and Economics Society Conference, Barcelona, Spain, 23-25 October 2014; pp. 369-377. [CrossRef]

7. Tomaskova, H.; Kuhnova, J.; Kuca, K. Economic model of Alzheimer's Disease. In Proceedings of the 25th International-Business-Information-Management-Association Conference, Amsterdam, The Netherlands, 7-8 May 2015; pp. 3120.

8. Tomaskova, H.; Kopecky, M.; Maresova, P. Process Cost Management of Alzheimer's Disease. Processes 2019, 7, 582. [CrossRef]

9. Kopecky, M.; Tomaskova, H. Activity Based Costing and Process Simulations. In Proceedings of the 17th International Scientific Conference on Hradec Economic Days, Hradec Kralove, Czech Republic, 5-6 Febuary 2019; pp. 431-438. 
10. Moreno-Cámara, S.; Palomino-Moral, P.; Moral-Fernández, L.; Frías-Osuna, A.; Parra-Anguita, L.; del Pino-Casado, R. Perceived Needs of The Family Caregivers of People with Dementia in a Mediterranean Setting: A Qualitative Study. Int. J. Environ. Res. Public Health 2019, 16, 993. [CrossRef]

11. Rinner, C.; Helm, E.; Dunkl, R.; Kittler, H.; Rinderle-Ma, S. Process Mining and Conformance Checking of Long Running Processes in the Context of Melanoma Surveillance. Int. J. Environ. Res. Public Health 2018, 15, 2809. [CrossRef]

12. Martínez Pérez, M.; Dafonte, C.; Gómez, A. Traceability in Patient Healthcare through the Integration of RFID Technology in an ICU in a Hospital. Sensors 2018, 18, 1627. [CrossRef]

13. García-Alfranca, F.; Puig, A.; Galup, C.; Aguado, H.; Cerdá, I.; Guilabert, M.; Pérez-Jover, V.; Carrillo, I.; Mira, J. Patient Satisfaction with Pre-Hospital Emergency Services. A Qualitative Study Comparing Professionals' and Patients' Views. Int. J. Environ. Res. Public Health 2018, 15, 233. [CrossRef]

14. Peeters, J.; Wiegers, T.; Friele, R. How Technology in Care at Home Affects Patient Self-Care and Self-Management: A Scoping Review. Int. J. Environ. Res. Public Health 2013, 10, 5541-5564. [CrossRef]

15. Catarci, T.; Leotta, F.; Marrella, A.; Mecella, M.; Sharf, M. Process-Aware Enactment of Clinical Guidelines through Multimodal Interfaces. Computers 2019, 8, 67. [CrossRef]

16. Russo, A.; Mecella, M. On the evolution of process-oriented approaches for healthcare workflows. Int. J. Bus. Process. Integr. Manag. 2013, 6, 224-246. [CrossRef]

17. Anyanwu, K.; Sheth, A.; Cardoso, J.; Miller, J.; Kochut, K. Healthcare enterprise process development and integration. J. Res. Pract. Inf. Tech. 2003, 35, 83.

18. van der Aalst, W.M.; Reijers, H.A.; Weijters, A.J.; van Dongen, B.F.; De Medeiros, A.A.; Song, M.; Verbeek, H. Business process mining: An industrial application. Inf. Syst. 2007, 32, 713-732. [CrossRef]

19. Mans, R.S.; Van der Aalst, W.M.; Vanwersch, R.J. Process Mining in Healthcare: Evaluating and Exploiting Operational Healthcare Processes, 1st ed.; Springer: Berlin/Heidelberg, Germany; New York, NY, USA, 2015.

20. Partington, A.; Wynn, M.; Suriadi, S.; Ouyang, C.; Karnon, J. Process mining for clinical processes: A comparative analysis of four Australian hospitals. ACM Trans. Inf. Syst. 2015, 5, 19. [CrossRef]

21. Garcia, A.O.; Ramírez, Y.E.P.; Larrea, O.U.A. Process Mining in Healthcare: Analysis and Modeling of Processes in the Emergency Area. IEEE Lat. Am. Trans. 2015, 13, 1612-1618. [CrossRef]

22. Stefanini, A.; Aloini, D.; Dulmin, R.; Mininno, V. Linking Diagnostic-Related Groups (DRGs) to their Processes by Process Mining. HEALTHINF 2016, 5, 438-443.

23. Pereira Detro, S.; Santos, E.A.P.; Panetto, H.; Loures, E.D.; Lezoche, M.; Cabral Moro Barra, C. Applying process mining and semantic reasoning for process model customisation in healthcare. Enterprise Inf. Syst. 2019. [CrossRef]

24. Kovalchuk, S.V.; Funkner, A.A.; Metsker, O.G.; Yakovlev, A.N. Simulation of patient flow in multiple healthcare units using process and data mining techniques for model identification. J. Biomed. Inform. 2018, 82, 128-142. [CrossRef]

25. Bard, F.; Cannon, C.; Barbour, R.; Burke, R.L.; Games, D.; Grajeda, H.; Guido, T.; Hu, K.; Huang, J.; Johnson-Wood, K.; et al. Peripherally administered antibodies against amyloid $\beta$-peptide enter the central nervous system and reduce pathology in a mouse model of Alzheimer disease. Nat. Med. 2000, 6, 916. [CrossRef]

26. Blurton-Jones, M.; Kitazawa, M.; Martinez-Coria, H.; Castello, N.A.; Müller, F.J.; Loring, J.F.; Yamasaki, T.R.; Poon, W.W.; Green, K.N.; LaFerla, F.M. Neural stem cells improve cognition via BDNF in a transgenic model of Alzheimer disease. Proc. Natl. Acad. Sci. USA 2009, 13594-13599. [CrossRef] [PubMed]

27. Dodart, J.C.; Bales, K.R.; Gannon, K.S.; Greene, S.J.; DeMattos, R.B.; Mathis, C.; DeLong, C.A.; Wu, S.; $\mathrm{Wu}$, X.; Holtzman, D.M.; et al. Immunization reverses memory deficits without reducing brain $\mathrm{A} \beta$ burden in Alzheimer's disease model. Nat. Neurosci. 2002, 5, 452. [CrossRef] [PubMed]

28. Joseph, J.A.; Arendash, G.; Gordon, M.; Diamond, D.; Shukitt-Hale, B.; Morgan, D.; Denisova, N. Blueberry supplementation enhances signaling and prevents behavioral deficits in an Alzheimer disease model. Nutr. Neurosci. 2003, 6, 153-162. [CrossRef] [PubMed]

29. Kuca, K.; Soukup, O.; Maresova, P.; Korabecny, J.; Nepovimova, E.; Klimova, B.; Honegr, J.; Ramalho, T.C.; França, T.C. Current approaches against Alzheimer's disease in clinical trials. J. Braz. Chem. Soc. 2016, 27, 641-649. [CrossRef]

30. Ujiie, M.; Dickstein, D.L.; Carlow, D.A.; Jefferies, W.A. Blood-brain barrier permeability precedes senile plaque formation in an Alzheimer disease model. Microcirculation 2003, 10, 463-470. 
31. Cimler, R.; Doležal, O.; Pscheidl, P. Comparison of RUST and C\# as a Tool for Creation of a Large Agent-Based Simulation for Population Prediction of Patients with Alzheimer's Disease in EU. In Proceedings of the International Conference on Computational Collective Intelligence; Springer: Berlin, Germany, 2016; pp. 252-261.

32. Dolezal, O.; Kakrda, P.; Cimler, R. Agent-Based Model of Ancient Siege Tactics. In Proceedings of the Asian Conference on Intelligent Information and Database Systems; Springer: Berlin, Germany, 2018; pp. 189-199.

33. Husáková, M. Combating infectious diseases with computational immunology. In Computational Collective Intelligence; Springer: Berlin, Germany, 2015; pp. 398-407.

34. Husáková, M. Representation of Autoimmune Diseases with RDFS. In Proceedings of the International Conference on Computational Collective Intelligence; Springer: Berlin, Germany, 2018; pp. 43-52.

35. Krenek, J.; Kuca, K.; Bartuskova, A.; Krejcar, O.; Maresova, P.; Sobeslav, V. Artificial neural networks in biomedicine applications. In Proceedings of the 4th International Conference on Computer Engineering and Networks. Shanghai, China, 19-20 July 2014; pp. 133-139.

36. Huang, L.F.; Cartwright, W.S.; Hu, T.w. The economic cost of senile dementia in the United States, 1985. Public Health Rep. 1988, 103, 3.

37. Jönsson, L. Economic evidence in dementia: a review. Eur. J. Health Econ. 2004, 5, s30-s35. [CrossRef]

38. Klimova, B.; Maresova, P.; Kuca, K. Non-pharmacological approaches to the prevention and treatment of Alzheimer's disease with respect to the rising treatment costs. Curr. Alzheimer Res. 2016, 13, 1249-1258. [CrossRef]

39. Leung, G.; Yeung, R.; Chi, I.; Chu, L. The economics of Alzheimer disease. Dement. Geriatr. Cogn. Disord. 2003, 15, 34-43. [CrossRef]

40. Maresova, P.; Mohelská, H.; Dolejs, J.; Kuca, K. Socio-economic aspects of Alzheimer's disease. Curr. Alzheimer Res. 2015, 12, 903-911. [CrossRef]

41. Schumock, G.T. Economic considerations in the treatment and management of Alzheimer's disease. Am. J. Health Syst. Pharm. 1998, 55, S17-S21. [CrossRef] [PubMed]

42. Wang, G.; Cheng, Q.; Zhang, S.; Bai, L.; Zeng, J.; Cui, P.J.; Zhang, T.; Sun, Z.K.; Ren, R.J.; Deng, Y.L.; et al. Economic impact of dementia in developing countries: an evaluation of Alzheimer-type dementia in Shanghai, China. J. Alzheimer's Dis. 2008, 15, 109-115. [CrossRef] [PubMed]

43. Klimova, B.; Maresova, P. Computer-based training programs for older people with mild cognitive impairment and/or dementia. Front. Hum. Neurosci. 2017, 11, 262. [CrossRef] [PubMed]

44. Klimova, B.; Maresova, P.; Kuca, K. Assistive technologies for managing language disorders in dementia. Neuropsychiatr. Dis. Treat. 2016, 12, 533. [PubMed]

45. Mls, K.; Cimler, R.; Mikulecky, P. Agent-based simulation for identifying the key advantages of intelligent environments for inhabitants with special needs. In Advanced Computer and Communication Engineering Technology; Springer: Berlin, Germany, 2016; pp. 1031-1041.

46. Nazem, A.; Mansoori, G.A. Nanotechnology solutions for Alzheimer's disease: advances in research tools, diagnostic methods and therapeutic agents. J. Alzheimer's Dis. 2008, 13, 199-223. [CrossRef]

47. Cartelli, V.; Di Modica, G.; Manni, D.; Tomarchio, O. A Cost-Object Model for Activity Based Costing Simulation of Business Processes. In Proceedings of the Modelling Symposium (EMS), Pisa, Italy , 21-23 October 2014; pp. 221-226.

48. Cartelli, V.; Di Modica, G.; Tomarchio, O. Extending the BPMN Specification to Support Cost-Centric Simulations of Business Processes. In Proceedings of the International Joint Conference on Knowledge Discovery, Knowledge Engineering, and Knowledge Management; Springer: Berlin, Germany, 2015; pp. 492-514.

49. Vasilecas, O.; Laureckas, E.; Rima, A. Analysis of using resources in business process modeling and simulation. Appl. Comput. Syst. 2014, 16, 19-25. [CrossRef]

50. Helzner, E.P.; Scarmeas, N.; Cosentino, S.; Tang, M.; Schupf, N.; Stern, Y. Survival in Alzheimer disease: a multiethnic, population-based study of incident cases. Neurology 2008, 71, 1489-1495. [CrossRef]

51. Xie, J.; Brayne, C.; Matthews, F.E. Survival times in people with dementia: analysis from population based cohort study with 14 year follow-up. BMJ 2008, 336, 258-262. [CrossRef]

52. Ressner, P. Alzheimerova choroba-diagnostika a léčba. Neurologie Pro Praxi 2004, 4, 11-16.

53. Jirák, R. Diagnostika a terapie Alzheimerovy choroby. Neurol. praxi 2008, 9, 240-244.

54. Stages of Alzheimer's. Available online: https://www.alz.org/alzheimers-dementia/stages (accessed on 16 April 2018). 
55. What Is BPM Anyway? Business Process Management Explained. Available online: https://www. bpminstitute.org/resources/articles/what-bpm-anyway-business-process-management-explained (accessed on 19 June 2019).

56. BPMN Specification-Business Process Model and Notation. Available online: http://www.bpmn.org/ (accessed on 10 April 2018).

57. Silver, B. BPMN Method and Style, 2nd ed.; Cody-Cassidy Press: Altadena, CA, USA, 2011; p. 286.

58. Nisler, J.; Tomaskova, H. BPMN as a Quality Tool for the Efficient Functioning of the Company. In Proceedings of the 30th International Business Information Management Association Conference, Madrid, Spain, 8-9 November 2017; pp. 3257-3263.

59. Tomaskova, H. Levels of Business Process Modeling. In Proceedings of the 30th International Business-Information-Management-Association Conference, Madrid, Spain, 8-9 November 2017; pp. 3495-3498.

60. Tomaskova, H. Modeling Business Processes for Decision-Making. In Proceedings of the 31st International Business Information Management Association Conference, Milan, Italy, 25-26 April 2018; pp. 4318-4321.

61. Dumas, M.; La Rosa, M.; Mendling, J.; Reijers, H.A. Fundamentals of Business Process Management; Springer: Berlin/Heidelberg, Germany, 2013; Volume 1, p. 399.

62. Business Process Model And Notation Version 2.0. Available online: https://www.omg.org/spec/BPMN/2. 0 (accessed on 10 April 2018).

(C) 2018 by the authors. Licensee MDPI, Basel, Switzerland. This article is an open access article distributed under the terms and conditions of the Creative Commons Attribution (CC BY) license (http://creativecommons.org/licenses/by/4.0/). 